Wilson:" Brit. Med. Jour., 1905, vol. ii, p. 706.

Winckel: Innaug. Dissert., Amsterdam, 1902.

Winter: Zeitschr. für Geburtsh. und Gynäk., Bd. xxxvii, Nr. 1.

Also Centralbl. für Gynäk., 1898, Nr. 19.

Wuerst: Innaug. Dissert., Leipzig, 1900

Zanobini: Quoted bylMichelini.

Zenalst: Innaug. Dissert., Kiel, 1899.

Zinke: Am. Jour. Obstet., No. 198, p. 828.

Zweifel: Vorlesungen ueber klin. Gynäk., 1892, Nr. 219. Also Frommel's Jahresb., 1894, s. 801.

\section{THE CLASSIFICATION OF THE MALARIAL} PLASMODIA.*

\author{
Captain, Medical Corps, United States Army.
}

From the discovery by Laveran of the malarial plasmodia to the present time, much attention has been devoted by zoölogists to the classification of these parasites, and many differing opinions have been advanced concerning their exact zoölogical position, and their division into genera and species. Laveran, believing in the unity of all malarial plasmodia, proposed the name "Oscillaria malarice" for the parasite infesting man, but later accepted Osler's name of "Hematozoon." In 1887, Metchnikoff placed these organisms among the Sporozoa, and proposed the name "Hematophyllum malaria" for the malarial parasite of man. Danilewsky created a division in the sporozoa which he called the hemosporidia, and in this division placed the malarial plasmodia. The genus plasmodium was created by Marchiafava and Celli, in 1885, and while, from a biological standpoint, the name is unfortunate, the law of priority in nomenclature requires that it be retained and that the parasites of malaria described as infesting man be all placed in this genus. Therefore, at the present time, it is conceded by all zoölogists that the parasites causing the malarial fevers of man belong to the Protozoa; order Sporozoa; sub-order, Hemosporidia, and genus, Plasmodium.

Although there is now no disagreement among investigators regarding the generic position of malarial plasmodia, there is still much uncertainty regarding the division of the parasites into species. Laveran and his followers believed that the parasite producing malaria in man is a polymorphous organism, varying very greatly in morphology under different conditions of environment, and that, as Laveran says, "There does not exist a constant relation between the forms under which the hematozoa appear in the blood and the clinical manifestations of paludism; one can only say that certain forms of the parasite are more often seen in certain cases, the crescents, for instance, in relapses, and in malarial cachexia." Some of Laveran's followers even claim to have observed interchangeability of the various species which have been described, but their observations still await confirmation.

The existence of distinct species of plasmodia associated with equally distinct types of malarial fever has been abundantly demonstrated by many careful observers, and the work of Marchia-

* Published with permission of the Surgeon-General, United States Army. fava and Bignami, Celli, Grassi and others, has resulted in the separation of several species of malarial plasmodia, differing in their morphology and life-history, as well as in the effects which they produce in man when blood containing them is inoculated directly or through the bite of infected mosquitoes. The great weight of evidence to-day, both morphological and experimental, is in favor of the existence of at least three species of malarial plasmodia, the tertian, quartan and estivo-autumnal, and these species have been accepted by nearly every investigator of the malarial fevers, although considerable uncertainty exists regarding the plasmodia causing the estivo-autumnal fevers, which have been placed by many observers in one species, while others believe that two species are concerned in the etiology of these fevers. The Italian authorities, together with nearly every investigator who has studied malaria in the tropics, have subdivided the estivo-autumnal plasmodia into at least two species, the quotidian and the tertian, and much has been written regarding the differentiation of these species and their specific characteristics. Some authorities believe in the existence of a pigmented and unpigmented quotidian plasmodium, and thus divide the estivo-autumnal plasmodia into three species, the tertian, and the pigmented and unpigmented quotidian plasmodia.

Personally I have no hesitation in stating that the estivo-autumnal plasmodia are divided into two distinct varieties: one, the tertian, being the type species; while the other, the quotidian, is a subspecies of the former. I have seen no evidence which leads me to believe in the existence of an unpigmented quotidian species, although I have examined the blood of thousands of patients suffering from estivo-autumnal infections.

Before suggesting a new classification of the malarial plasmodia, which is the purpose of this paper, several of the classifications proposed for these parasites will be briefly considered, as they have all been adopted at various times, and many are still adhered to by writers upon these fevers.

Grassi and Feletti's classification. - These authors placed all of the malarial parasites in two genera, Hemameba and Laverania. In the genus Hemameba they mention four species of malarial parasites as occurring in man: Hemameba malarice (quartan), Hemameba vivax (tertian), Hemameba precox (pernicious), and Hemameba immaculata (pernicious).

In the genus Laverania, they placed the crescentic parasites, giving them the specific name "Laverania malarice" but in this case neither the generic or specific name can stand, as both were founded upon the belief that the crescents were a distinct species of plasmodium. Mannaberg's classification. - Mannaberg divides the malarial plasmodia as follows:

1. Malarial parasites that sporulate, but do not form syzygies (crescents).

(a) Quartan plasmodium. (b) Tertian plas- 
2. Malarial parasites that sporulate and form syzygies (crescents).

(a) Pigmented quotidian plasmodium. (b) Unpigmented quotidian plasmodium. (c) Malignant, tertian plasmodium.

Mannaberg did not name any of these plasmodia. Sacharoff's classification. - This author divided the plasmodia into two genera, Hemameba and Laverania; in the first genus he included three species as follows:

Hemameba precox (estivo-autumnal) Grassi. Hemameba febris tertiance (tertian) Golgi. Hemameba febris quartance (quartan) Golgi.

In the second genus he included one species characterized by a crescentic shape. In this he followed Grassi and Feletti, believing that the the crescents were a distinct species of plasmodium.

Luhe's classification. - The classification of Luhe, which is recent and has been accepted by many authorities, divides the malarial plasmodia into two genera, Laverania and Plasmodium. In the genus Laverania he places the estivoautumnal plasmodium, while in the genus Plasmodium he places the tertian and quartan parasites. According to Luhe the malarial plasmodia of man should be classified as follows: Genus, Laverania. Species, Laverania malaria, Grassi and Felletti, 1890. Estivo-autumnal.

Genus, Plasmodium. Species, Plasmodium malarice, Marchia and Celli. Quartan.

Plasmodium vivax, Grassi and Feletti. Tertian parasite.

As has been stated, the generic term "Laverania" cannot be retained, as it was applied to one phase of the estivo-autumnal plasmodia by Grassi and Feletti, who believed this phase, or the crescents, to be a distinct species of plasmodium.

Schaudinn's classification. - The classification of the malarial plasmodia most generally adopted to within a very recent date by zoölogists and students of malaria has been that of Schaudinn, who placed all malarial plasmodia infesting man in the genus Plasmodium, dividing them into three species, as follows:

(1) Plasmodium vivax, Grassi and Feletti. Tertian parasite. (2) Plasmodium malario, Marchia and Celli. Quartan parasite. (3) Plasmodium immaculatum, Grassi and Feletti. Estivoautumnal parasite.

However, the specific name " immaculatum" can no longer be retained for the estivo-autumnal plasmodium, as Blanchard has shown that Grassi previously used this name for a parasite occurring in birds, thus preventing its use for the human parasite. This fact renders the specific name " falciparum," proposed by Welch, the proper name for the estivo-autumnal plasmodium, and Blanchard's classification, which follows, is the most recent and generally accepted of the many which have been proposed.

Blanchard's classification. - This classification divides the plasmodia of malaria into one genus,

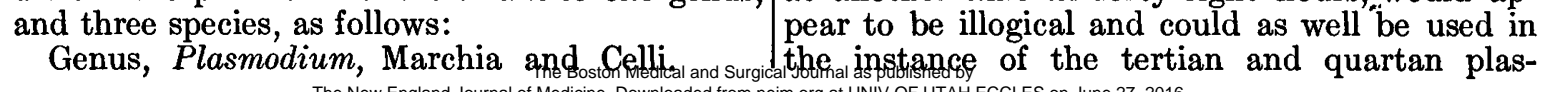

Species: (1) Plasmodium malarice, Marchia and Celli. Quartan parasite. (2) Plasmodium vivax, Grassi and Feletti. Tertian parasite. (3) Plasmodium falciparum, Blanchard. Estivoautumnal parasite.

For those who believe in only one species of the estivo-autumnal plasmodium, the classification of Blanchard is the correct one, but it cannot be accepted by those who believe in plurality of species as regards the estivo-autumnal parasites.

While nearly all authorities admit the existence of three species of human malarial plasmodia, the tertian, quartan and estivo-autumnal, the question of the existence of more than one species of the latter organism is still an undecided one. By many authorities the estivoautumnal plasmodia are divided into two species, a tertian and quotidian, while by some the quotidian is subdivided into a pigmented and unpigmented quotidian parasite. Other authorities maintain that there is but one estivo-autumnal plasmodium, the variations observed in the temperature in infected individuals being due to variations in the length of the developmental cycle, which may be at one time twenty-four hours and at another, forty-eight hours long.

During the past ten years I have had the opportunity of studying the plasmodia in thousands of cases of malarial fever of the estivo-autumnal type and have reached the conclusion that two plasmodia are concerned in the etiology of such infections, one sporulating in twenty-four hours; the other, in forty-eight hours. These two species were first described by Marchiafava and Bignami, and there is no doubt in my mind that they can be easily distinguished morphologically when material is available, and that in uncomplicated cases they each produce a characteristic form of fever. Any one who can differentiate the tertian and quartan plasmodia morphologically should have but little trouble in distinguishing between the tertian and quotidian estivo-autumnal plasmodia, if blood from the spleen, obtained by puncture, be examined. To one who has had the opportunity of studying a large number of cases of infection with both species, they may be readily distinguished by the forms occurring in the peripheral blood. I have not been able to demonstrate the existence of a pigmented and unpigmented quotidian plasmodium as specifically distinct forms, for while it is not uncommon to observe only unpigmented quotidian plasmodia in the peripheral blood in estivo-autumnal infections, the spleen invariably shows pigmented organisms, and, as a rule, an extended search will reveal pigmented organisms in the peripheral blood.

The argument that the tertian and quotidian temperature curves observed in estivo-autumnal infections are due to the sporulation of a plasmodium, which at one time completes its developmental cycle in man in twenty-four hours and at another time in forty-eight hours, would appear to be illogical and could as well be used in the instance of the tertian and quartan plasFor personal use only. No other uses without permission. From the NEJM Archive. Copyright $\odot 2010$ Massachusetts Medical Society. 
modia by those who still maintain that there is but one species"ofiplasmodium.

In view of my belief that the estivo-autumnal fevers are due to two distinct parasites, a view held by many other investigators who have studied malaria in the tropics, and as, to my knowledge, the quotidian plasmodium has never received a specific name, I propose for that organism the name "Plasmodium falciparum quotidianum," regarding it as a sub-species of Plasmodium falciparum, which is concerned in the etiology of tertian estivo-autumnal malaria. The latter organism is undoubtedly typical of the estivo-autumnal plasmodia, and for that reason I regard it as the type, and the quotidian plasmodium as a sub-species. The classification of the malarial plasmodia proposed would then be as follows:

Division. Protozoa.

Class. Sporozoa.

Order. Hemosporidia.

Genus. Plasmodium.

Species:

1. Plasmodium malarice, Marchia et Celli. Quartan malarial plasmodium.

2. Plasmodium vivax, Grassi et Feletti. Tertian malarial plasmodium.

3. Plasmodium falciparum, Blanchard. Estivo-autumnal plasmodium, tertian type.

Sub-species:

4. Plasmodium falciparum quotidianum, Craig, 1909. The quotidian estivo-autumnal plasmodium.

\section{Elinical gdepartment.}

\section{A CASE OF SEROUS AMICROBIC MENINGITIS. OPERATION. RECOVERY.*}

BY ChanNing C. SIMmons, M.D. Surgeon to Out-Patients, Massachusetts General Hospital; Assistant
in Surgery, Harvard Medical School.

The following case is of interest as regards the diagnosis and the condition found at operation. There has been considerable interest in recent years in cerebral injuries and intracranial surgery. Formerly injuries to the head other than fracture of the skull and middle meningeal hemorrhage were classed as concussion or contusion and the treatment was what might be termed expectant, - rest, lowering of blood pressure by drugs and depletion, ice to the head, etc. Now, however, certain of the cases have been recognized as conditions which may best be relieved by surgical interference, but even at present there is considerable difference of opinion among neurologists as to the value of an operation in a given case. Cushing, in this country, is a strong advocate of decompression if the condition is at all doubtful, as it can be done rapidly and with comparatively little shock. In the following case there was considerable difference of opinion as to the advisability of operation among the neurologists, and although it is im-

* The author wishes to express his thanks to Dr. W. A. Brooks for the opportunity to operate upon and report this case. possible to say what the outcome would have been without operation, it seems improbable that recovery would have been as rapid.

R. P., fourteen years of age, was brought to the accident room of the Massachusetts General Hospital on Sept. 25, 1908, with the following history.

On Sept. 9 he went to the county fair. That night the family heard a noise and thought nothing of it, but made an investigation an hour later and found the patient in his night clothes, unconscious, at the foot of a flight of stairs. Examination at that time by Dr. Willard showed no bleeding from the ears or nose. The breathing was quiet and the pulse slow. There was a swelling in the left temporo-parietal region, and ecchymosis over the right eyebrow. The jaws were set in spasm. There was flaccid paralysis on the right arm, but the other extremities were moved when the patient was disturbed. The pupils were equal and reacted to light.

For six days the patient remained in practically the same condition, unconscious most of the time, with periods of violence. The bowels were moved by enemas, and feeding accomplished by rectum. He had incontinence of urine and lay always on the left side. Paresis of the right leg was noticed.

A week after the injury there was some improvement in his condition. The movements were more purposive, and he took a small amount of nourishment by mouth, but he would not answer questions; the paralysis remained the same and there was still incontinence. There was no improvement for four days before admission to the hospital.

Previous history. - Always well and considered a bright boy. Headache at times for the past three months. No vomiting, convulsions or other brain symptoms.

Physical examination. - Well-developed boy; semiconscious, lying on left side. When turned patient protests and rolls back. Makes no response to questions.

Cranium negative. No bleeding from ears or nose. Pupils equal and react; examination of fundus shows no choked disk. Slight right facial paralysis. Iungs negative. Heart slow, sounds loud, no murmurs. Pulse 40 and of high tension; temperature $97^{\circ}$ by rectum. All extremities cold and bluish, especially the right arm, which shows complete muscular paralysis. Abdominal and cremasteric reflexes more marked on left than right: Patellar, Achilles and plantar reflexes normal; Kœnig's sign present on both sides. No rigidity of neck.

The patient was seen in consultation with Dr. Waterman, who advised a decompression operation, without opening the dura, for possible hemorrhage, or, more probably, laceration of the cortex.

The patient was kept under observation for twentyfour hours. During this time he was semi-conscious, with periods of restlessness and extreme violence. There was incontinence of urine. The pulse varied between 28 and 44, averaging about 40, and was of high tension, but unfortunately the blood pressure was not taken.

Operation Sept. 26. A curved incision was made with the convexity upwards, beginning at the border of the hairy scalp over the external canthus, and ending over the auditory meatus. Flap dissected back and fibers of temporal muscle separated, exposing the skull. Button removed with trephine over the lower end of the Rolandic area, that is, somewhat higher than the usual opening for hemorrhage from the anterior branch of the meningeal artery. There was no evidence of meningeal hemorrhage. The presenting dura bulged into the opening, was pale and did not 